HETEROCYCLES, Vol. 95, No. 1, 2017, pp. 1-2. @ 2017 The Japan Institute of Heterocyclic Chemistry DOI: 10.3987/COM-16-S(S)Foreword_1

\title{
PREFACE TO HETEROCYCLES ISSUE HONORING THE 70TH BIRTHDAY OF PROFESSOR DR. MASAKATSU SHIBASAKI
}

Congratulations, Professor Shibasaki! It is a great pleasure and honor for me to deliver some words to this special issue of HETEROCYCLES on the occasion of his 70th birthday.

Professor Masakatsu Shibasaki was born in Konosu in Saitama Prefecture, Japan in 1947 . He entered the University of Tokyo in 1965 and received Ph.D. in 1974 at the Graduate School of Pharmaceutical Sciences of the same university under the supervision of the late Professor Shun-ichi Yamada. After working as a postdoctoral fellow at Prof. E. J. Corey's group at Harvard University for three years, he joined Professor Ikegami's group at Teikyo University as a lecturer. In 1983 he was appointed as a team leader at Sagami Chemical Research Center (SCRC). I know Professor Shibasaki since I joined his group at SCRC in 1985. We engaged in the total synthesis of marine natural product, punaglandin 4. After the completion of the total synthesis in 1986, I was assigned to join a different research group in SCRC. Therefore, we worked together only one year at SCRC. Soon after, in the middle of 1986, Professor Shibasaki moved to Hokkaido University as a Professor of the Faculty of Pharmaceutical Sciences at the age of 39. In the beginning of 1988, he picked me up as an assistant professor in his group, and we started the chemistry of rare earth catalysis along with the synthesis of advanced analogue of phorbol derivatives. After he moved to the University of Tokyo in 1991, he kindly gave me a position at his group as a lecturer and then as an associate professor until I moved to the present position at Osaka University. At that period of time he always encouraged me and other colleagues, and showed the best research topic to be studied. We could develop several heterobimetallic catalysts and revealed their unique feature as a "cooperative catalyst", which is now recognized as an important concept for the design of effective asymmetric catalysts.

In the beginning of 2017 , he will be 70 years old. Asian people often celebrate 70 th birthday as "Koki" in Japanese, which means "Men seldom live to be seventy", which originally came from a Chinese poem written about 1300 years ago by Tu Fu. However, nowadays, most of the men at 70 years old are healthy and Professor Shibasaki as well. Indeed, he is still quite active as a scientist after he moved to The Institute of Microbial Chemistry in 2010, as a director, and published about 100 articles including eight papers in J. Am. Chem. Soc. and 18 papers in Angew. Chem. Int. Ed. In total, he has reported more than 700 papers, which have been cited about 40,000 times. Professor Shibasaki is an excellent mentor as well as a leading scientist. He always showed appropriate information about the vacant academic positions to his colleagues and students even in the case they played an important role in 
his project. As a result, we can find a number of his former colleagues and students in the world of academia, including more than 20 full professors. In this special issue of HETEROCYCLES, some of them contribute their interesting results. On behalf of Professor Shibasaki's former and present colleagues and students, I would like to express my sincere wish for his happy "Koki" and healthy, prosperous, and fruitful seventies.

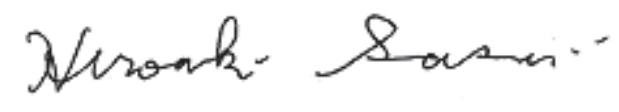

\section{Hiroaki Sasai \\ Osaka, Japan}

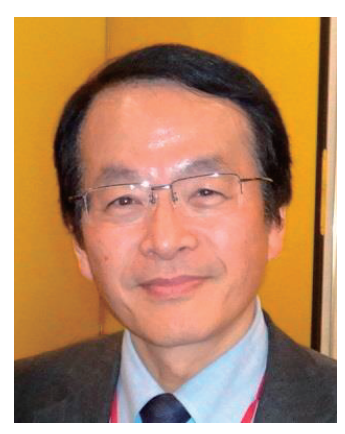

Hiroaki Sasai graduated from Keio University in 1980 and received his doctor degree in 1985 from Keio University. After working as a researcher at Sagami Chemical Research Center for three years, he joined Prof. Shibasaki's group at Hokkaido University as an assistant professor. In 1992, he moved to the University of Tokyo, and in 1997 he was appointed as a full professor of the Institute of Scientific and Industrial Research (ISIR), Osaka University. He stayed at University of Bourgogne in 2013 as a Visiting Professor. He was a recipient of 1995 Pharmaceutical Society of Japan Award for Young Scientists, and the Fluka Prize "Reagent of the Year 1996" (with Prof. Shibasaki). He received The Chemical Society of Japan Award for Creative Work and Ichimura Science Award in 2006, the Molecular Chirality Award in 2011, and Synthetic Organic Chemistry Award in 2016. His current research interest is in the area of enantioselective catalysis and conceptually new functional materials. 